\title{
Adult-onset mast cell activation syndrome following scombroid poisoning: a case report and review of the literature
}

\author{
Isabelle Brock ${ }^{1,2,4^{*}} \mathbb{D}$, Nicole Eng ${ }^{5}$ and Anne Maitland ${ }^{1,3}$
}

\begin{abstract}
Background: Mast cells are closely associated with epithelium, serving as sentinels responsible for the recognition of tissue injury and coordination of the initial inflammatory response. Upon detection of the injured cell content, mast cells then tailor the release of preformed and newly produced chemical mediators to the detected challenge, via an array of pathogen receptors. In addition to immunoglobulin E receptor-triggered mast cell activation, commonly referred to as allergic or atopic disorders, non-immunoglobulin E receptor mediated mast cell activation follows engagement of toll-like receptors, immunoglobulin G receptors, and complement receptors. Upon containment of the extrinsic challenge, acute inflammation is downregulated, and repair of the injured tissue ensues. The mast cell compartments must return to a baseline steady state to remain tolerant towards self-antigens and harmless entities, including environmental conditions, to prevent unnecessary immune activation and chronic hypersensitivity disorders. Over the past 50 years, an increasing number of patients are experiencing episodes of aberrant mast cell activation, not associated with allergen-specific mast cell disease or systemic mastocytosis. This led to proposed diagnostic criteria of mast cell activation syndrome. Mast cell activation syndrome is a heterogeneous disorder, defined by a combination of (1) recurrent symptoms typical of mast cell activation, (2) an increase of validated mast cell derived mediators, and (3) response to treatment with mast cell stabilizing or mast cell mediator-targeted therapies. Onset of mast cell activation syndrome ostensibly reflects the loss of tolerance in the mast cell compartment to nonthreatening entities and nonhazardous environmental conditions. The etiology of chronic mast cell dysregulation and associated intolerance to self-antigens or harmless entities is not well understood, but a growing number of studies point to exposure of the epithelial borders, which leads to inappropriate or excessive mast cell activation or impaired resolution of acute inflammation following neutralization of the identified pathogen.
\end{abstract}

Case presentation: Here we present a case of adult onset mast cell activation syndrome following scombroid poisoning. Scombroid toxicity is usually a self-limited illness, but there are individuals who have been shown to have severe symptoms or persistent illness following histamine fish poisoning. We describe a 74-year-old Caucasian woman, with a history of drug-induced urticaria, who developed a constellation of hypersensitivity illnesses consistent with the diagnosis of mast cell activation syndrome after ingestion of tainted fish.

Conclusion: Mast cell activation disease causes problems of increased complexity in children and adults. The increased prevalence and severity of mast cell activation disease has been attributed to dramatic changes in our lifestyles and modern living environments. These changes likely impact the integrity of the epithelial barriers, leading

*Correspondence: research@connective-tissue-issues.com

2 Qolify, 99 Wall St Suite 1147, New York, NY 10005, USA

Full list of author information is available at the end of the article original author(s) and the source, provide a link to the Creative Commons licence, and indicate if changes were made. The images or other third party material in this article are included in the article's Creative Commons licence, unless indicated otherwise in a credit line to the material. If material is not included in the article's Creative Commons licence and your intended use is not permitted by statutory regulation or exceeds the permitted use, you will need to obtain permission directly from the copyright holder. To view a copy of this licence, visit http://creativecommons.org/licenses/by/4.0/. The Creative Commons Public Domain Dedication waiver (http://creativeco mmons.org/publicdomain/zero/1.0/) applies to the data made available in this article, unless otherwise stated in a credit line to the data. 
to loss of tolerance in the mast cell compartment. Here, we present a case of a nonatopic, 74-year-old female who developed mast cell activation disease after exposure to a potent environmental toxin. Mast cell activation disease commonly involves several organ systems, with patients often referred to a succession of different specialists. This results in delayed diagnosis and suboptimal care. Instead, early recognition of mast cell activation disease would lead to better outcomes. We review the literature, describing the diagnostic criteria for mast cell activation disorders that can improve recognition of this multiorgan system syndrome. Further research is needed into the interaction of epithelial barrier disruption and the dysregulation of the immune system.

Keywords: Mast cell, Mast cell activation syndrome, Scombroid poisoning, Histamine, Tryptase, Epithelium, Tolerance, Immune homeostasis

\section{Case report Background}

Mast cells are closely associated with epithelium, serving as sentinels responsible for the recognition of tissue injury and coordination of the initial inflammatory response. Upon detection of the injured cell content, mast cells then tailor the release of preformed and newly produced chemical mediators to the detected challenge, via an array of pathogen receptors. In addition to immunoglobulin E (IgE) receptor-triggered mast cell activation (MCA), commonly referred to allergic or atopic disorders, non-IgE mediated mast cell activation follows engagement of toll-like receptors (TLRs), immunoglobulin $\mathrm{G}$ (IgG) receptors, and complement receptors. Upon containment of the extrinsic challenge, acute inflammation is downregulated, and repair of the injured tissue ensues. The mast cell compartments must return to a baseline steady state, to remain tolerant towards selfantigens and harmless entities, including environmental conditions, to prevent unnecessary immune activation and chronic hypersensitivity disorders.

Over the past 50 years, an increasing number of patients are experiencing episodes of aberrant mast cell activation, not associated with allergen specific mast cell disease or systemic mastocytosis. This led to proposed diagnostic criteria of mast cell activation syndrome (MCAS). MCAS is a heterogeneous disorder, defined by a combination of (1) recurrent symptoms typical of MCA, (2) an increase of validated mast cell-derived mediators, and (3) response to treatment with mast cell stabilizing or MC mediator-targeted therapies. Onset of MCAS ostensibly reflects the loss of tolerance in the mast cell compartment to nonthreatening entities and nonhazardous environmental conditions. The etiology of chronic mast cell dysregulation and associated intolerance to self-antigens or harmless entities is not well understood, but a growing number of studies point to exposure of the epithelial borders, which leads to inappropriate or excessive mast cell activation or impaired resolution of acute inflammation following neutralization of the identified pathogen.

\section{Case presentation}

A 74-year-old Caucasian woman, with a past medical history of arrhythmia, breast cancer with bilateral mastectomy, an acoustic neuroma, menopause, hypothyroidism, and chronic musculoskeletal complaints, presented to the emergency department (ED) with intense redness of her face and hands, burning sensation involving her face and neck, palpitations, a "pounding headache," difficulty breathing, dysphagia, and a rapid heart rate. Her illness began shortly after eating a tuna burger from a local fish market. She denied previous incidents of food intolerance or anaphylaxis. In the past, the patient had only used prescription or over-the-counter antihistamines for drug induced urticaria, opiate pain relievers, and nonsteroidal antiinflammatory drugs (NSAIDs). Both pain relievers had been avoided for years.

Upon arrival in the ED, her vital signs were body temperature of $97.0^{\circ} \mathrm{F}\left(36.1{ }^{\circ} \mathrm{C}\right)$, pulse of 120 beats per minute (bpm), blood pressure of $123 / 55 \mathrm{mmHg}$, oxygen concentration of $99 \%$ on room air, and a respiration rate of 16 breaths per minute. She also reported chest pain, with a level of $5 / 10$. On physical examination, she was found to have an erythematous facial rash and complained of diffuse itching. The patient was administered prednisone $60 \mathrm{mg}$ and diphenhydramine $50 \mathrm{mg}$, with relief of her headache, rash, chest pain, and pruritis. In addition, an electrocardiogram revealed sinus tachycardia, at $107 \mathrm{bpm}$, and she was ultimately diagnosed with a cardiac arrhythmia. No other laboratory tests were ordered. Two samples of the tuna steak were obtained from the local fish market, which sickened four adults with scombrotoxinism. The samples contained histamine levels of $500 \mathrm{ppm}$ and $4850 \mathrm{ppm}$, both greater than the threshold of less than $50 \mathrm{ppm}$ deemed nontoxic by federal regulation. Since both the patient and her husband exhibited allergic-like reactions to the tuna burger, scombroid poisoning was suspected.

Unlike her husband, who was treated and recovered from this episode of scombrotoxinism, the patient experienced persistent urticaria and angioedema, with the diagnosis of new onset dermatographism, following 
completion of the 5-day course of oral prednisone and diphenhydramine from the initial ED visit. Despite the use topical corticosteroids and daily levocetirizine $5 \mathrm{mg}$, loratadine $40 \mathrm{mg}$, and fexofenadine $180 \mathrm{mg}$, the patient experienced daily symptoms, for the next 6 weeks. The patient returned to the local emergency department for persistent facial swelling and difficulty swallowing following ingestion of crab cakes for dinner, which had been tolerated in the past. The patient reported difficulty swallowing, sensation of food getting stuck, increased throat clearing, and nasal congestion, as well as numbness and tingling of the tongue, lips, and throat. In the local ED, the patient was found to have a body temperature of $98.2^{\circ} \mathrm{F}\left(36.8{ }^{\circ} \mathrm{C}\right)$, a pulse of $106 \mathrm{bpm}$, blood pressure of $140 / 65 \mathrm{mmHg}$, oxygen concentration of $98 \%$ on room air, and a respiration rate of 18 breaths per minute. On physical examination, an erythematous facial rash was reported, and the patient was evaluated by an otolaryngologist in the ED, given new onset dysphagia. The otolaryngologist reported erythema of the laryngeal mucosa. The patient was discharged with a course of famotidine $20 \mathrm{mg}$, prednisone $40 \mathrm{mg}$, and diphenhydramine $25 \mathrm{mg}$.

Following this visit to the ED, the patient underwent an evaluation by a local allergy specialist. Recurrent urticaria was noted, and laboratory tests revealed the following: total serum immunoglobulin E (IgE) of $16 \mathrm{IU} /$ $\mathrm{mL}$; total complement level within normal limits; undetectable serum IgE for insect venoms, tuna, and crab; undetectable autoantibodies to nuclear antigen (ANA); a negative recommended avoidance of all seafood.

The patient sought another opinion with our practice, regarding chronic urticaria and new onset shellfish allergy, 1 month after her last ED visit and 6 months after scombroid poisoning. She had continued her regimen of thrice daily histamine receptor-1 blockade and famotidine $20 \mathrm{mg}$ twice daily. In addition to the recurrent flushing, rhinitis complaints, dyspepsia, and episodic dysphagia, the patient cited chest tightness at rest, in the evening, and on exertion. Spirometry revealed an obstructive pattern consistent with reversible airway disease, which exhibited a modest improvement following administration of levalbuterol $0.63 \mathrm{mg} / 3 \mathrm{~mL}$. Another set of laboratory tests were ordered, with the following results: serum tryptase of 4.8 and a serum IgE
$17 \mathrm{IU} / \mathrm{mL}$, which were comparable to previous results, but a plasma histamine level of $13 \mathrm{nmol} / \mathrm{L}$ was detected (normal range $0-8 \mathrm{nmol} / \mathrm{L}$ ) (Table 1 ).

The patient maintained a limited diet, given her history of new onset shellfish allergy, and carried an epinephrine autoinjector and a short-acting beta agonist inhaler for the anaphylaxis and asthma, respectively. The patient opted for treatment with omalizumab for chronic urticaria, and was prescribed $300 \mathrm{mg}$, administered every 4 weeks, since she was still symptomatic despite thrice daily antihistamines, twice daily leukotriene modifiers, and oral and inhaled cromolyn preparations.

Following her first dose of omalizumab, the patient complained of increased pruritis, flushing, and chest tightness, prompting another ED visit. The patient required epinephrine administration for a grade two, drug-induced anaphylactic event. Following another course of oral corticosteroids and diphenhydramine, the patient underwent a graded challenge to omalizumab. Over a 3-month period, omalizumab $150 \mathrm{mg}$, administered every 2 weeks, was successfully reintroduced [1]. As recently reported, the addition of omalizumab, is the standard care for patients with MCAS.

The diagnosis of MCAS in this patient, following scombroid poisoning, is supported by detection of increased mast cell derived mediators. Following anaphylaxis, to crab meat and then to the first administration of omalizumab, we tested for validated markers of mast cell activation within a few hours of each suspected MCA event (Table 1). An elevated serum histamine level was detected following ingestion of crab meat and her first omalizumab administration. After her third episode of anaphylaxis, serum histamine returned to baseline, but serum tryptase also reduced to $2.2 \mu \mathrm{g} / \mathrm{mL}$ from her previous recorded values, which ranged from 4.8 to $5.2 \mu \mathrm{g} / \mathrm{mL}$. Along with the constellation of recurrent symptoms of mast cell activation, including chronic urticaria, asthma, and susceptibility to anaphylaxis, and a partial response to histamine and leukotriene blockade, the detection of an elevated plasma level following episodes of anaphylaxis, and a reduction of serum tryptase of greater than $2 \mu \mathrm{g} / \mathrm{mL}$ and $>20 \%$, led to the diagnosis of nonclonal mast cell activation syndrome (MCAS) (Table 2).

Table 1 Results of serial testing of tryptase and histamine between 2014 and 2015

\begin{tabular}{|c|c|c|c|c|c|c|}
\hline & Ref. range & $12 / 20 / 2014$ & $2 / 10 / 2015$ & $2 / 12 / 2015$ & $2 / 22 / 2015$ & $8 / 7 / 2015$ \\
\hline \multirow[t]{2}{*}{ Tryptase } & $2-10 \mathrm{ng} / \mathrm{mL}$ & 4.8 & 4.7 & 2.2 & 5.2 & 5.0 \\
\hline & Ref. Range & $\begin{array}{l}10 / 17 / 2014 \\
15: 09\end{array}$ & $\begin{array}{l}12 / 17 / 2014 \\
18: 52\end{array}$ & $\begin{array}{l}12 / 20 / 2014 \\
03: 59\end{array}$ & $\begin{array}{l}2 / 11 / 2015 \\
12: 32\end{array}$ & $\begin{array}{l}8 / 7 / 201 \\
5 \\
14: 44\end{array}$ \\
\hline Histamine & $0-8 \mathrm{nmol} / \mathrm{L}$ & $13(H)$ & $<8$ & $16(H)$ & $<8$ & $<8$ \\
\hline
\end{tabular}


Table 2 Proposed criteria for mast cell activation syndrome (all three criteria must be present) (Akin, 2017)

\begin{tabular}{ll}
\hline Mast cell activation disease (MCAD), includes individual mast cell activation disorders and mast cell activation syndrome (MCAS) \\
\hline Individual mast cell activation disorders & Skin: urticaria, angioedema, flushing \\
& Gastrointestinal: nausea, vomiting, diarrhea: abdominal cramping/pain, gastroesophageal reflux disease \\
& Cardiovascular: hypotensive syncope or near syncope, tachycardia \\
& Neuropsychiatric: brain fog, anxiety, depression, paresthesia, lightheadedness \\
& Respiratory: wheezing \\
& Naso-ocular: conjunctival injection, pruritus, nasal congestion, posterior rhinorrhea \\
& Genitourinary: pain with urination, urinary frequency; females - pain with intimate relations; heavy, painful \\
& menses \\
& Musculoskeletal: bone pain, muscle pain, degenerative disc disease, osteopenia/osteoporosis \\
& (1) In addition to two or more of the above-mentioned MCA disorders \\
(2) An elevated biomarker for mast cell activation syndrome, which can include semi tryptase or urinary \\
mediators, such as prostaglandin and histamine metabolites (prostaglandin 1)2, 11 Beta Prostaglandin F2 \\
Alpha, or methylhistamine \\
(3) A decrease in the frequency, severity, or resolution of symptoms with histamine receptor antagonists or \\
other mast cell-targeted medications, such as ketotifen, omalizumab, cromones, or tricyclic agents
\end{tabular}

Upon reaching the maintenance dose of omalizumab $150 \mathrm{mg}$, every 2 weeks, the patient was able to expand her diet and reduce her daily medical regimen to control her asthmatic condition and chronic spontaneous urticaria. In addition to omalizumab, the patient is maintained on daily levocetirizine, chlorpheniramine, zafirlukast, and famotidine. Moreover, under ongoing treatment her quality of life was improved, including less disrupted sleep, resumption of outdoor exercise, reintroduction of food stuffs, except seafood, and less frequent urticarial outbreaks.

\section{Discussion}

Over the past 50 years, there has been a rise in classic mast cell activation disorders, such as rhinitis, food hypersensitivity, anaphylaxis, urticaria, and asthma, as well as less well known MCAD, such as neuropsychiatric and musculoskeletal syndromes. A growing number of pediatric and adult patients are experiencing recurrent episodes of MCA, not associated with allergen-specific mast cell activation disease or systemic mastocytosis. This led to proposed diagnostic criteria of mast cell activation syndrome, which includes the following: (1) systemic mast cell activation involving two or more organ systems, in parallel; (2) an increase in validated mast cell markers during symptomatic episodes; and (3) having a major response to medications that block MCA or inhibit the action of MC-derived mediators (Table 2). The diagnosis of mast cell activation syndrome (MCAS) is appropriate, when all three criteria are met $[2,3]$.

Mechanisms contributing to rise of mast cell activation disorders, including MCAS, have not been established. Studies have implicated environmental exposures from modern living leading to excessive mast cell-initiated acute inflammation, or impaired resolution of inflammation following neutralization of the offending agent. This case report demonstrates the onset of MCAS in a 74-year-old woman following exposure to scombrotoxin.

Scombroid poisoning, or histamine fish poisoning, is a toxic event with symptoms and treatment that mimic anaphylaxis. Scombroid poisoning results from consumption of mishandled fish. Histamine and other decomposition products are generated in time-temperature abused raw fish by bacterial, enzymatic conversion of free histidine. The onset of scombroid poisoning is typically from 10 minutes to 1 hour following consumption of poisonous fish. The symptoms are variable and include peppery or metallic taste, oral numbness, headache, dizziness, palpitations, rapid and weak pulse (low blood pressure), difficulty in swallowing, and thirst. Scombroid poisoning often mimics allergen-specific IgE-triggered mast cell activation, with symptoms such as hives, rash, flushing, facial swelling, nausea, vomiting, abdominal cramps, and diarrhea. Less specific symptoms such as anxiety are less frequently observed [4].

Recovery is usually complete within 24 hours, but in rare cases can last for days. For example, serious cardiovascular compromise and respiratory complications have been observed, and in a few unusual cases, hospitalization, including treatment for anaphylaxis $[5,6]$. There are two reports of patients developing chronic mast cell activation disorders following scombroid poisoning: after ingesting decomposed tuna, a 21-year-old woman, with a history of intermittent asthma, developed poorly controlled asthma, requiring multiple ED visits and five daily medications to control new onset, 
severe persistent asthma. Another woman, without a history of MCADs, was diagnosed with adult-onset rhinitis and asthma following scombroid poisoning [7, 8].

Scombroid poisoning is associated with elevated histamine levels in the outbreak-associated samples. However, there is not a clear dose-response relationship between oral administration of histamine and the magnitude of toxicity associated with scombroid poisoning [5]. Interestingly, several studies point to the impact of "histamine releasing factors" on the epithelium and closely associated mast cells, by enteric, gram-negative bacteria found in the fish cutis and intestines. These include Escherichia coli, Klebsiella species, Pseudomonas aeruginosa, and Morganella morganii [4]. As reported in animal models of anaphylaxis and asthma, loss of tolerance in the mast cell compartment can be induced by exposure to chemical adjuvants and microbial-derived substances, such as aluminum hydroxide and lipopolysaccharides, respectively [9-11]. Combined with signals of tissue injury, called alarmins or damage associated molecular patterns (DAMPs), the microbial-derived substances are potent stimulants of mast cell activation.

With this patient, the reportedly high levels of histamine detected in the two samples of tuna from this seafood market greatly exceeded the level of histamine deemed toxic by the US Food and Drug Administration (FDA), more than $50 \mathrm{mg} / 100 \mathrm{~g}$ of tuna (50 ppm). Such high levels of histamine ostensibly reflect the burden of scombrotoxins, which in turn induced epithelial damage and delivered large quantities of histamine to the poisoned diners of the tainted fish. That is, the combination of histamine and histamine release factors, scombrotoxins, may have either severely disrupted the epithelium border and consequently caused a pronounced MCA event, or interfered with the processes that resolve inflammation after the acute insult has been neutralized. Three of the four adults with scombroid poisoning made a full recovery within 24 hours with conservative medical management. In contrast, our patient, with a distant history of druginduced urticaria, required daily medication for adultonset spontaneous inducible urticaria/angioedema, hypersensitivity gastroenteritis, and moderate persistent asthma, starting in the seventh decade of life. In addition to diet restriction, including avoidance of seafood, gluten, cow's milk, soybean, and nuts, she must carry an epinephrine autoinjector and short-acting beta agonist inhaler given her history of anaphylaxis and intrinsic asthma exacerbations, following scombroid poisoning [12].

\section{Conclusion}

In summary, we describe the clinical presentation of a presentation of MCAS following scombroid poisoning. The diagnosis is appropriate given her combination of (1) typical symptoms, (2) laboratory abnormalities, and (3) response to treatment. Following scombroid poisoning, adult-onset chronic urticaria/angioedema evolved into susceptibility of anaphylaxis, chronic hypersensitivity gastroenteritis, and moderate persistent asthma. Symptomatic episodes were associated with an elevation in validated mast cell markers, both serum tryptase and histamine, and her symptoms came under better control with the addition of omalizumab, the anti-immunoglobulin E monoclonal antibody, to her daily regimen of cromolyn antihistamines and leukotriene blockade. Despite the rise of immediate hypersensitivity disorders, it is not uncommon for MCAS to be diagnosed late, as observed with our patient. This leads to delayed recommendations for more effective treatment prescriptions of medications, with adverse effects; both of which may contribute to progressive disease. As recently described, the greatest hurdle to diagnosis and management of MCAS is to correctly attribute appropriate symptoms to this disorder, and timely measurement of validated mast cell activation markers. The latter will differentiate $\mathrm{MC}$ activation disorders from other syndromes with overlapping symptomology $[12,13]$. This case also provides insight into potential etiologies and risk factors for development of MCAS.

Mast cell dysregulation can be due to a mutation affecting homeostasis of the mast cell compartment, clonal MCAS (mastocytosis, hyper alpha tryptasemia), or extrinsic factors driving aberrant MCA. Although the etiology of this newly recognized hypersensitivity syndrome is unknown, the course of events leading to adult-onset MCAS in this patient points to the disruption of the epithelial barrier by scombrotoxins. This, in turn, disrupted the tight regulation of this tissue-based, innate immune cell population, and increased susceptibility to mast cell activation events. Animal models and epidemiological studies support this theory of recurrent or severe injury to the epithelium in susceptible children and adults leading to development of immediate and delayed hypersensitivity syndromes: disruption of the epithelial barrier leads to loss of regulation of the mast cell compartment. This, in turn, leads to increased susceptibility of unnecessary inflammation, from impaired barrier function, and implicates the use of therapeutics targeting epithelialmast cell interactions in preservation or restoration of immune homeostasis $[10,14]$.

\section{Abbreviations}

MC: Mast cells; MCAS: Mast cell activation syndrome; TLR: Toll-like receptors; IgR: Immunoglobulin receptors; CR: Complement receptors; ARDS: Acute 
respiratory distress syndrome; PAMPs: Pathogen associated molecular pattern; POTS: Postural orthostatic tachycardia syndrome; hEDS: Hypermobile type Ehlers-Danlos syndrome; PID: Primary immunodeficiency; ACE2: Angiotensinconverting enzyme 2; DAMPs: Damage-associated molecular patterns.

\section{Acknowledgements}

None.

\section{Authors' contributions}

Both authors have contributed in equal parts to all parts of the study and manuscript.

\section{Funding}

This work received no funding.

\section{Availability of data and material}

The datasets used and analyzed during the current study are available from the corresponding author on reasonable request.

\section{Declarations}

\section{Ethics approval and consent to participate}

Ethics approval and consent to participate was given by the patient

\section{Consent for publication}

Written informed consent was obtained from the patient for publication of this case report and any accompanying images. A copy of the written consent is available for review by the Editor-in-Chief of this journal.

\section{Competing interests}

Isabelle Brock has no conflicts to declare. Anne Maitland receives compensation as part of the speakers' bureau of Sanofi Pharmaceuticals, Regeneron, and Genentech. There is no conflict of interest with the observations reported in this manuscript and Dr. Maitland's affiliation.

\section{Author details}

${ }^{1}$ Comprehensive Asthma and Allergy, 200 S Broadway Suite 104, Tarrytown, NY 10591, USA. ${ }^{2}$ Qolify, 99 Wall St Suite 1147, New York, NY 10005, USA. ${ }^{3}$ Department of Neurology, Mount Sinai- South Nassau Hospital, The ChiariEDS Center, 1420 Broadway, Hewlett, NY 11557, USA. ${ }^{4}$ Department of Medical and Molecular Genetics, Indiana University School of Medicine, 975 W. Walnut Street, IB 130, Indianapolis, IN 46202, USA. ${ }^{5}$ Nicole Eng, BS, Biomedical Studies, University of Pittsburgh, Pittsburgh, USA.

Received: 11 April 2021 Accepted: 12 November 2021

Published online: 18 December 2021

\section{References}

1. Dreyfus DH, Randolph CC. Characterization of an anaphylactoid reaction to omalizumab. Ann Allergy Asthma Immunol. 2006;96:624-7.

2. Akin C. Mast cell activation syndromes. J Allergy Clin Immunol. 2017;140:349-55.

3. Hamilton MJ. Non-clonal mast cell activation syndrome: a growing body of evidence. Immunol Allergy Clin North Am. 2018;38(3):469-81.

4. Stratta P, Badino G. Scombroid poisoning. Can Med Assoc J. 2012;184(6):674.

5. Hungerford JM. Scombroid poisoning. Toxicon. 2010;56:231-43.

6. Sanchez-Guerrero IM, Vidal JB, Escudero Al. Scombroid fish poisoning: a potentially life-threatening allergic-like reaction. J Allergy Clin Immunol. 1997;100:433-4

7. Lohiya G-S, Lohiya S, Lohiya S, Krishna V. Scrombrotoxinism: protracted illness following misdaignosis in the emergency department. Case Rep Emerg Med. 2015;76:1-4.

8. Wilson BJ, Musto RJ, Ghali W. A case of histamine fish poisoning in a young atopic woman. J Gen Intern Med. 2012;27:878-81.

9. Finkelman FD. Anaphylaxis: lessons from mouse models. J Allergy Clin Immunol. 2007;120:506-15.
10. Platts-Mills TAE. The allergy epidemics: 1870-2010. J Allergy Clin Immunol. 2015;136(1):3-13. https://doi.org/10.1016/j.jaci.2015.03.048.

11. Subbarao P, Mandhane PJ, Sears MR. Asthma: epidemiology, etiology and risk factors. CMAJ. 2009. https://doi.org/10.1503/cmaj.080612.

12. Weiler CR, Austen KF, Akin C, Barkoff MS, Bernstein JA, Bonadonna P, Schwartz LB, et al. AAAAI mast cell disorders committee work group report: mast cell activation syndrome (MCAS) diagnosis and management. J Allergy Clin Immunol. 2019;144(4):883-93.

13. Valent $P$, Akin C. Doctor, I think I am suffering from MCAS: differential diagnosis and separating facts from fiction. J Allergy Clin Immunol Pract. 2019;7(4):1109-14. https://doi.org/10.1016/j.jaip.2018.11.045.

14. Schleimer RP, Berdnikovs S. Etiology of epithelial barrier dysfunction in type 2 inflammatory diseases. J Allergy Clin Immunol. 2017;139(6):1752-61.

15. Theoharides TC, Valent $P$, Akin C. Mast cells, mastocytosis, and related disorders. N Engl J Med. 2015;373:163-72. https://doi.org/10.1056/NEJMr a1409760.

16. Kahn D. Alternative agents in refractory chronic urticaria: evidence and considerations on their selection and use. J Allergy Clin Immunol Pract. 2013;1:433-40

17. Chieffi Baccari G, Pinelli C, Santillo A, Minucci S, Rastogi RK. Mast cells in nonmammalian vertebrates: an overview. Int rev Cell Mol Bio. 2011:290:1-53

18. Galli SJ, Tsai M. Mast cells in allergy and infection: versatile effector and regulatory cells in innate and acquired immunity. Eur J Immunol. 2010;40(7):1843-51.

\section{Publisher's Note}

Springer Nature remains neutral with regard to jurisdictional claims in published maps and institutional affiliations.

Ready to submit your research? Choose BMC and benefit from:

- fast, convenient online submission

- thorough peer review by experienced researchers in your field

- rapid publication on acceptance

- support for research data, including large and complex data types

- gold Open Access which fosters wider collaboration and increased citations

- maximum visibility for your research: over 100M website views per year

At BMC, research is always in progress.

Learn more biomedcentral.com/submissions 